\title{
Unsettling Pedagogy: Co-Designing Research in Place with Indigenous Educators
}

\author{
LAURA SCHAEFLI \\ Queen's University, Canada
}

\author{
ANNE GODLEWSKA \\ Queen's University, Canada
}

ABSTRACT This article argues that decolonizing educational research begins in attention to inherited colonial thinking and ways of being. Working with over 250 Indigenous educators, staff, students, faculty and administrators associated with 10 partner universities in Ontario, Canada, we co-designed a questionnaire assessing how Ontario post-secondary students are learning to think about colonialism and its relationship to Indigenous peoples and Canadian society. Situating ourselves as researchers and as participants, we theorize the questionnaire's and our own methodological transformation through the lens of recent literature on epistemologies of ignorance, discussing humour, the relationship between language and imagination, and assumptions we held that presented significant opportunities to shift how we relate. In doing so we argue the social importance of attending to the limits of knowledge and the entrenchment of those limits in historically conditioned and socially sanctioned axes of dominance. We attest both to the depths of colonial misrecognition and to the power of Indigenous knowledge and ways of being to shift social worlds.

KEYWORDS decolonization; education; settler colonialism; Indigenous peoples; ignorance; Canada; Ontario

Attempting to build non-violent knowledge must, perhaps, inevitably be done along the frontier - between worlds, between cultures and languages, between histories and territories. What tools do we have? Many, including the law, history, the archive, the academy, and writing itself, have also been the tools of colonialism. And given the history of our world, could it be any other way? To build non-violent knowledge with tools steeped in violence may be the core of our project.

Florencia Mallon, Decolonizing Native Histories (2011, p. 18)

Correspondence Address: Laura Schaefli, Department of Geography \& Planning, Queen's University, Kingston, ON, K7L 3N6; Email: laura.schaefli@queensu.ca 
The assumption held by dominant cultures and our pedagogies and research programs - that everything is in principle knowable - forms not only the epistemological basis for our being and knowing but also our fantasies and desires for a better, less fragmented world. Such progressive desires are important, but they must also be seen as based in fantasy - a redemptive fantasy of unity that attempts to overcome history and ongoing effects of colonization. Such fantasy is a necessary but always troubled ingredient in cross-cultural work.

Alison Jones with Kuni Jenkins, Working the Indigene-colonizer hyphen (2008, p. 17)

This article argues that decolonizing educational research begins with attention to inherited colonial thinking and ways of being. Coalescing at the height of European colonial expansion in the $18^{\text {th }}$ and $19^{\text {th }}$ centuries, many of the modern disciplines, including geography, anthropology, history and law, have been instrumental in developing and defending systems of thought and practice that serve to legitimate colonial exploitation (Chakrabarty, 2009; Fabian, 1982; Godlewska \& Smith, 1994; MaldonadoTorres, 2007). These ways of thinking work to render the dispossession of Indigenous bodies and territories as just, certain and inevitable, by portraying Indigenous worldviews and practices as moral and intellectual failures, always waiting for and in need of correction and completion, in the name of spiritual, economic and social advancement (Fanon, 1967; Povinelli, 2011; Smith, 2012). As Kikuyu novelist and scholar Ngũgĩ Wa Thiong'o argues, achieving, consolidating and justifying control of territory, the foundation of extractive economic and political relations, demands inculcation of systems of thought that frame such relations as not only legitimate, but inevitable. Colonization requires ignorance of the beauty of other forms of relation (Wa Thiong'o, 1994). In this article, we argue the decolonial importance of attending to the limits of knowledge and the entrenchment of those limits in historically conditioned and socially sanctioned axes of dominance. Drawing on our experiences developing a research project that seeks to center the knowledge, experiences and ways of being of Indigenous people and communities in decolonizing formal education in Canada, we suggest the nature and subtleties of colonial ignorance, defined not as a passive or incidental absence of knowledge, but as the outcome of ways of understanding the world and one's place in it that are socially-sanctioned, cultivated across social realms, and deeply linked to racialized, gendered, classed, anthropocentric and intersecting forms of power (Medina, 2013; Sullivan \& Tuana, 2007). Situating ourselves as both researchers and participants (Bodone, Gudónsdóttir \& Dalmau, 2004; Norris, 2008), we engage in critical reflection on the shifts in language and consciousness engendered through working with over 250 First Nations, Métis and Inuit educators and community members to codesign a research tool that expresses their concerns and interests. The aim 
of the research tool is to investigate how high school graduates in the most populous province in Canada are trained to think about colonialism and its relationship to First Nations, Métis and Inuit peoples and Canadian society. Our focus here is not on the results of that research, which have been published elsewhere (Godlewska, Rose, Schaefli, Freake \& Massey, 2016; Godlewska et al., 2017; Godlewska, Schaefli, Massey, Freake \& Rose, 2017; Schaefli et al., 2018; Schaefli, Godlewska \& Rose, 2018; Schaefli, Godlewska \& Lamb, 2019), but on the tensions and points of connection involved in the collaborative work of designing a research tool.

We approach our reflections here through the lens of recent scholarship on ignorance (May, 2006; Medina, 2013; Schaefli \& Godlewska, 2014; Steyn, 2012; Sullivan \& Tuana, 2007). Although the study of knowledge and its nature has been the focus of Western thought since ancient times, it is only recently that scholars, Western and not, are beginning to grapple with ignorance as a social and political phenomenon in its own right. We draw the work of critical Indigenous and decolonial theorists on ignorance to suggest the importance of attending to "the force field of colonialism's conceptual web, in which many more of us than often acknowledged remain entangled" (Stoler, 2016, p. 9). Thinking otherwise, as Michel Foucault reminds us, is always the critical challenge.

\section{The Colonial Nature of Ignorance}

Indigenous leaders and activists in the settler colonial context of Canada emphasize how colonial ignorance functions to maintain exploitative relations between the Canadian state and First Nations, Métis and Inuit peoples. This ignorance, they argue, is not a neutral or incidental absence of knowledge, waiting to be filled. Rather, it is epistemological, a logic that works to uphold the ontological hierarchies from which racism and colonialism thrive (Calderon, 2014; Kuokkanen, 2011; Manuel \& Derrickson, 2017). This logic is rooted in historic operational practices that favour particular methods of perception and function to foreclose "otherthan-dominant epistemes and refuse to seriously contemplate their existence" (Kuokkanen, 2008, p. 63). Ignorance is institutionalized, promoted through law, political structures, popular modes of representation, and especially education, in ways that work to naturalize racialized hierarchies of being and knowing and refuse the systemic and enduring nature of colonial oppression (Battiste, 2013; Kuokkanen, 2011). Understood in this way, ignorance is a powerful social force, because it works at personal and social levels in ways that are constantly reinforcing. An epistemology of ignorance works to justify and maintain extractive political, economic, and social relations, while encouraging unawareness of how subjectivity is shaped by the social positions, power relations and ways of knowing that emerge from colonial, racial and patriarchal oppression 
(Fricker, 2007; Medina, 2013; Sullivan \& Tuana, 2007). Deeply embedded in the everyday, in the national and personal imaginary and in accepted assumptions behind fundamental concepts such as nature, wilderness, science, good governance, order and wellbeing, an epistemology of ignorance is difficult to challenge. At the heart of settler epistemological certainty lies settler self-interest in maintaining the status quo.

In 2015, the Truth and Reconciliation Commission of Canada (TRC) on the history and legacy of the Indian Residential School system (1870s-1996) called upon ministries of education, school boards, universities, colleges and teachers to commit to remedying mass ignorance. Citing the "broad lack of understanding of the unjust and violent circumstances from which modern Canada emerged," the Commission made the nation-to-nation relationship enshrined in the 1763 Royal Proclamation and the 2007 UN Declaration on the Rights of Indigenous Peoples the guiding principle of its work (Sinclair, 2015, n.p.; TRC, 2015). Challenging and altering the imagination of people in Canada about this relationship, the TRC argued, is fundamental to meaningful social transformation (TRC, 2015). Indigenous leaders and activists have long fought for greater community input in the design of inclusive, culturally responsive, anti-oppressive education (Assembly of First Nations, 1972, 1988; Battiste, 2013; Kirkness, 1999). Building on this work, the Calls to Action of the Truth and Reconciliation Commission have prompted educational institutions across Canada to enhance their efforts to identify and confront the systemic prejudice embedded in course content, funding priorities, administrative decisionmaking, and the priorities of teachers, teacher educators, faculty and staff. The research tool and larger project discussed here engages with and works to support efforts to decolonize education, by exploring, in quantitative and qualitative terms, the relationship between formal education and Canadians' "significant lack of understanding and respect for First Nations, Métis and Inuit ways of understanding the world, which translates into a lack of understanding of First Nations, Métis and Inuit rights in Canada" (Turner, 2006, p. 8). Following Linda Tuhiwai Smith's observation that "Real power lies with those who design the tools," the Awareness project involved codesigning a questionnaire with Indigenous educators from communities associated with participating universities and colleges, as well as Indigenous and non-Indigenous staff members, academics, students, and administrators (Smith, 1999, p. 38). The questionnaire includes a test of student knowledge and questions about students' education, attitudes and demographics. Such a tool must allow fine-grained analysis of the relationship between knowledge considered by Indigenous educators to be vital to responsible citizenship, and post-secondary students' formal education, attitudes, and experience. As the questionnaire seeks to assess student understanding of colonialism in Canada, it is vital that the questions be grounded in the understanding, experiences and wisdom of First Nations, 
Métis and Inuit people who best understand the implications of Canada's colonial nature.

Using an established social science tool to help overturn established ways of thinking might seem quixotic. The aim of the research is not only to reveal ignorance, but also to encourage educational institutions and students themselves to address it seriously. Thus, the research must use some of the language and techniques of education management, at least to some degree. We designed the co-design process we discuss here to make us responsible primarily to Indigenous educators and community leaders and to ground the critical nature of the project in personal experience of oppression. Understanding this oppression profoundly is what helped us to frame questions that can break down the congratulatory narratives structuring most Canadians' understanding of their history and society. With Indigenous collaborators, this project has sought to challenge the colonial thinking that structures education across Canada. There are other ways of challenging this thinking, including publication, films, representational and non-representational art, fiction, protests, lobbying and other strategies by Indigenous and non-Indigenous people. This project seeks to add to these efforts, by taking an approach directed at the heart of ignorance in Canada: its educational institutions. The co-design process required the generous and willing contribution of Indigenous people, support - at least minimal of higher-level administration at educational institutions, our displacement to institutions and sometimes communities across Ontario, and the willing participation of undergraduate students. The co-design process put the research in a perpetually precarious position with respect to the power relations between Indigenous people, university administrations, students, and academic research.

Valuing the learning and experience of students, Indigenous and not, was a major concern for the research team. The distance between Indigenous knowledge holders and students created by an online survey risked retrenching colonial modes of relation: reducing experience to consumable facts. For this reason, we have begun to deliver the Awareness questionnaire in university classes, in the presence of paid Elders, and with the support of university and college administrators and instructors. Completing the questionnaire in class signals that the topics are important to the educational institution. The questionnaire reveals the answers to multiple-choice questions as the students complete them and, at the end of the questionnaire, directs students to a resource webpage of works principally by Indigenous thinkers. Our methodology now combines grassroots co-design with the basic principles of survey design and on the ground delivery to help make visible the deep entrenchment of colonial ignorance in Canadian society and the role of formal education in perpetuating it. 


\section{Unsettling Pedagogy}

Analyzing colonial ignorance from within a colonial society poses significant challenges, foremost amongst which is decolonizing our own ways of thinking and being, as a Swiss newcomer and recent permanent resident of Canada (Laura), and as a Canadian citizen and a child of Polish and French World War II refugees (Anne). As privileged beneficiaries of a colonial system in which whiteness "enhances one's life chances as configured through the logic of capital" and as academics trained in the Western academy, we bring sets of experiences, relationships, and knowledges shaped profoundly by the power and advantage these embodiments signify and accrue in contemporary dominant political and socio-economic systems (Moreton-Robinson, 2015, p. xx). We also bring an abiding commitment to use the resources available to us to center and amplify Indigenous voices. As critical Indigenous and decolonial theorists argue, decolonization is a structure, not an event, requiring on-going critical consciousness of the systemic nature of oppression, its articulation along racialized, gendered, classed, and anthropocentric lines, the distortion of history, our own collaboration, and every day, subtle, tenuous moments of conscious action towards relating otherwise (Dhamoon, 2015; RedwingSaunders \& Hill, 2007). In research contexts, this entails undoing the opacity of academic knowledge production, foregrounding the researcher as part of the research, making legible the interests the research serves, being open about difficulties and failures, and orienting the research in ways that support the on-going enactment of Indigenous knowledge traditions (Denzin, Lincoln \& Smith, 2008; Patel, 2014). In this article we lay out our experiences of the methodological and epistemological negotiations embedded in the co-design of the first-year Awareness questionnaire, as we carried it out in Ontario in 2013-2014 with over 250 First Nations, Métis and Inuit knowledge holders from communities associated with 10 Ontario universities, as well as staff, academics, students, and administrators. ${ }^{1}$ This entailed approximately 60 meetings with sometimes as few as one person and as many as 30 over a period of 10 months and a total travel distance of 16,000 kilometres (about 10,000 miles). To each meeting we brought the survey, as modified by previous co-designers, and reviewed each question, word-for-word, for importance, accuracy, and resonance with co-designers' experience and understanding. The questionnaire underwent considerable evolution as a result of this process, as did we. We learned because we came informed by reading of critical Indigenous theorists and worked faceto-face with knowledge holders in their homes and places of work or community, a process of "falling into embodied awareness of living in Indigenous sovereignty" (Nicoll, 2004, p. 17). In such places co-designers

\footnotetext{
${ }^{1}$ These universities are: University of Windsor, University of Guelph, Wilfrid Laurier University, McMaster University, University of Toronto, Trent University, Queen's University, University of Ottawa, Laurentian University and Lakehead University.
} 
shared what they felt and we used all of our senses to understand their meaning. Some co-designers expressed considerable anger at governmental and settler strategies that so favoured us and others and so denigrated them. In situations where the impact of the loss of land, the undercutting of identity, and the absence of resources was clear, we were "unfixed and uncomfortable" and in that discomfort came to understand (Daza, 2008, p. 76; Regan, 2010). We trace the questionnaire's and our own "methodological becoming" through the co-design meetings and offer critical reflections on them, discussing the key role of our institutional partners, the importance of humour, the relationship between language and imagination, and assumptions we held that presented significant opportunities to shift how we relate (Mountz, Miyares, Wright \& Bailey, 2003, p. 29).

There are some dangers to deliberating over this project of co-design and our experiences of it in an academic paper. Focusing on changes to the questionnaire and our own consciousness risks reinforcing a liberal pedagogical model that frames consumption of knowledge-about-the-other as the endpoint of justice. Such a pedagogical approach is deeply problematic, as it is oriented around desire to secure the goodness and redemption of "those who now know," rather than around naming and disrupting systemic and organizational structures of racism and colonialism, a dynamic that is itself deeply racialized (Ahmed, 2005; Jones with Jenkins, 2008). We approach the problem of ignorance not in this liberal pedagogical sense of a gap to be filled, but as a social and structuring force linked to material and epistemological inheritance. Focusing on ignorance in this sense is important for three reasons. First, it foregrounds the material nature of ignorance: absences, exclusions, and failures to imagine otherwise are present, real, and organize the way the world, shaped by colonialism, functions (de Sousa Santos, 2005). Second, it emphasizes that decolonization is not an endpoint but a demanding and on-going process, requiring constant attention to the limits of understanding or "care of the self" (Ettlinger, 2011, p. 551; Tuck \& Yang, 2012). Lastly, it suggests the transformative possibilities afforded by humility, generosity, and uncertainty, not in the sense of the "resilience" and "flexibility" celebrated and promoted through neoliberalism, but as an on-going, self-conscious refusal to mobilize the "axiomatic knowledge and action that have emerged from fantasies of colonial entitlement and certainty" (Mackey, 2016, p. 132). In this paper and in our co-design research, we attest both to the depths of colonial misrecognition and to the power of Indigenous knowledge and ways of being to shift social worlds. 


\section{The Indigenous Origins of the Research}

At the very earliest conceptual origins of this research in 2007, Jackie Moore, the director of the Aboriginal Teachers Education Project at Queen's, alerted Anne to the existence of the Walking in Beauty study. In 2004 the Canadian Race Relations Foundation-funded Learning About Walking in Beauty report suggested that, in spite of significant social change in Canada since the 1970s, most young Canadians were learning little more about Aboriginal life and issues than did their parents' parents (CAAS, 2004). The Coalition for the Advancement of Aboriginal Studies (CAAS) offered the questionnaire they developed to describe and address this ignorance to anyone prepared to continue the effort. Puzzled by the deep ignorance of students in our classes and the apparent willingness of many to learn, we wanted to explore the nature and causes of colonial ignorance. Using the CAAS questionnaire as a base, we developed our own process, which evolved to an approach much closer to theirs over time. Both the CAAS study and this one involve consultation with Indigenous people and academics, are educational, allow qualitative analysis, and release all data and tests upon project completion. With greater resources, we were able to involve more students in more institutions, in more parts of the country and maintain the study over a longer time.

\begin{tabular}{|l|l|l|}
\hline \multicolumn{1}{|c|}{ Study differences } & \multicolumn{1}{|c|}{$\begin{array}{c}\text { Walking in Beauty } \\
\text { (CAAS Study) }\end{array}$} & $\begin{array}{c}\text { Addressing Awareness } \\
\text { (Our Study) }\end{array}$ \\
\hline \hline Population Sampled & Not available & $40,000-50,000$ \\
\hline Sample Size & 519 & $5,000-10,000$ \\
\hline Administrative Partners & No & Yes \\
\hline Delivery Mode & In class & In class \& online \\
\hline Statistical Analysis & No & Yes \\
\hline Regionally Specific & No (1 test) & Provincial \\
\hline Target & College \& University & University, years 1 \& 4 \\
\hline Duration & 1 year & Multi-year \\
\hline Demographic Questions & 4 & 21 \\
\hline
\end{tabular}

Table 1. Differences Between the Walking in Beauty and Addressing Awareness Studies.

For the duration of the Ontario study, we were unable to secure funding for the research. The first years of the project coincided with the years of the Conservative Harper government's majority in Canada. Funding cuts to organizations such as Canada Race Relations (which had funded the CAAS study) and the budgets allotted to federal granting agencies put significant pressure on critical research. In addition, the political atmosphere permitted 
shutting down socially critical research. Consequently, the time consuming and geographically demanding delivery of the survey to classrooms was impossible for research in Ontario (survey delivered 2014) or Newfoundland and Labrador (survey delivered 2013). Since, in our research in British Columbia and Manitoba and for our $4^{\text {th }}$-year survey in Ontario, we have surveyed students in classrooms with the support of Indigenous Elders wherever possible.

Indigenous educational leaders at each university are the most critical people to the co-design. The unique position of these leaders, bridging the gap between highly privileged educational institutions and Indigenous communities, allowed us to connect with individuals and organizations whose insight formed the questionnaires. We worked most often with Directors of the Indigenous Student Centre at each university. Off-campus community leaders, friendship centres, and educational institutions on reserves gave generously of their time and insight because of their high regard for the work of these Indigenous educators and advocates and their interest in the problem of settler ignorance. The quality of relationships Indigenous leaders had built was also evident in the number of people we met with on campus and the range of their experience (Indigenous student services staff, faculty, undergraduate and graduate students, members of the university's Aboriginal Education Council, Elders in Residence, equity advisors, top level administrators). Committed to practical results, at meetings they observed the interactions and gave gentle advice. Universities worked with us, facilitated meetings and in some cases shared student data. The questionnaire's transformation is summarized in Table 2.

It is clear from this graphic that we modified every question. We eliminated questions from all themes and most of these eliminations occurred early on in the process as co-designers made clear which questions were important and which were less so. We added 13 new questions, only two of which we later eliminated. Some environments were especially critical: our earliest meeting with a university was in column 2 and at the university in column 12, co-designers adapted the questionnaire to issues in northern Ontario, which resulted in many changes to questions. 


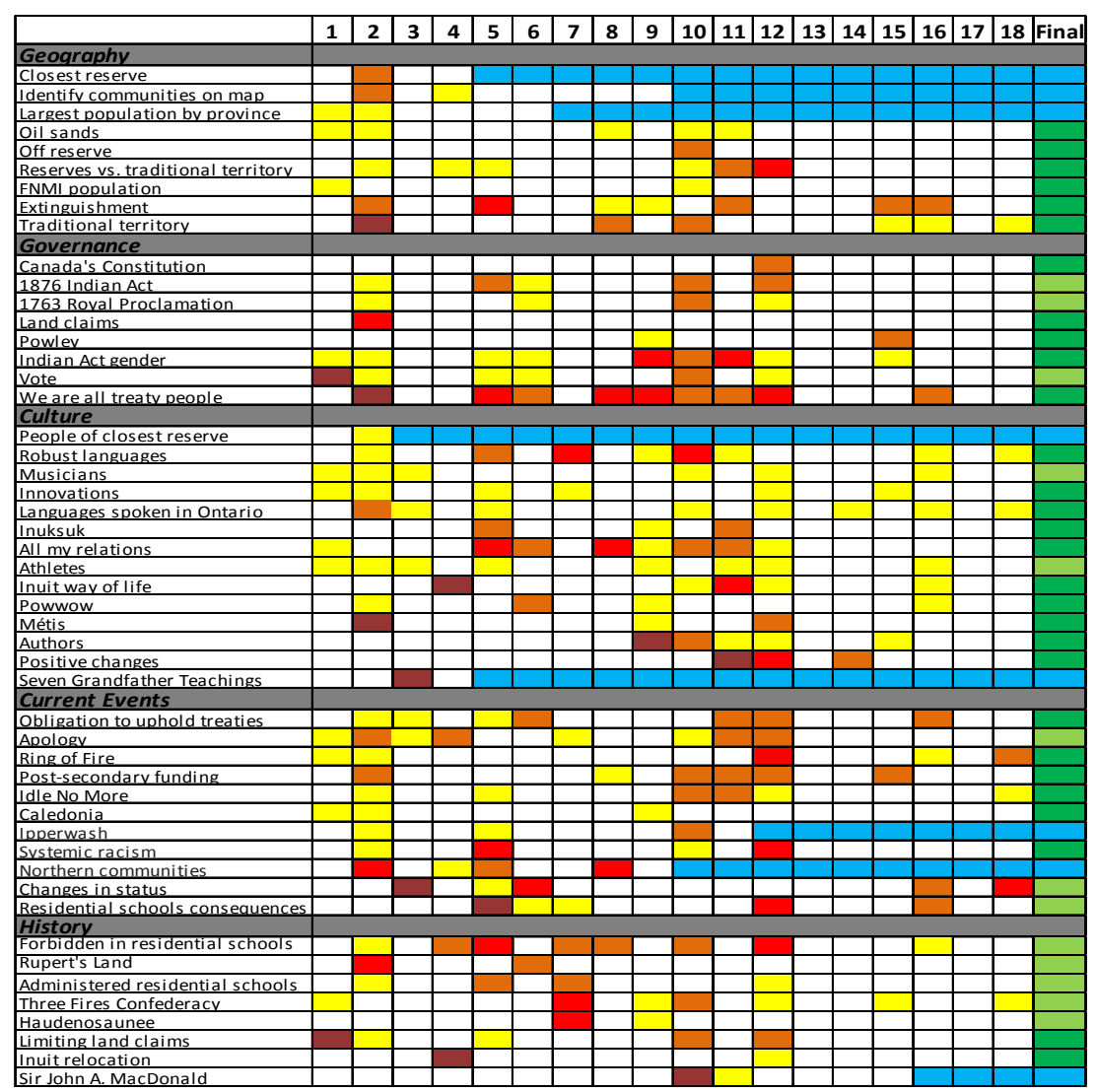

Table 2. Summary of Co-design Changes to the Ontario Awareness Questionnaire, 2013-2014.2

\section{Learning Co-design: The Social Environments of Meetings}

Dedicated to challenging comfortable Canadian assumptions, from its earliest days this project sought to build open, self-critical and radically receptive relationships with Indigenous people(s) and experiences. Traveling to meet co-designers in their cultural and personal homelands put into sharper relief the inherited epistemological baggage we carried with us. As representatives, however reluctant, of an oppressive educational system

\footnotetext{
${ }^{2}$ Each column represents a group of co-design meetings of generally two to four days. Test questions and themes are on the left. Retained questions are in dark green on the right. The remaining colors indicate the following: light green - mentioned in the k-12 curriculum; blue question eliminated; purple - a new question; red - a major rewrite; orange - a moderate rewrite; yellow - minor rewording.
} 
and society, we often encountered suspicion and from time to time hostility (though always restrained) (on the tensions associated with non-Indigenous researchers in Indigenous communities, see Donald, 2012; Kovach, 2010; Louis, 2007; Smith, 1999; and Wilson, 2008). In these early moments (or hours), silence and sometimes pointed questioning tested the authenticity of our co-design approach and our intentions, which made us better perceive our expectations and open ourselves to ways of relating differently (Bell, 2008). The ice was broken and we knew we were indeed co-designing when colleagues burst into laughter, teased us or told an amusing story. Humour often opened the way to a new level of exchange. As we learned, we became more adept at discerning layers of meaning in criticism of the questions.

Sometimes humour worked to mark a shift in trust. It was suggested to us by Kanonhsyonne (Janice Hill), then Director of the Four Directions Aboriginal Centre at Queen's, to offer tobacco at the start of our co-design meetings. We brought small sachets of tobacco to our first meeting in Ontario with Mohawk educators. After introducing ourselves and the project, we placed a sachet before each of the eight people present (Wilson and Restoule, 2010). Only one person immediately accepted the gift. In these early days we were discomforted by this, unsure whether we could continue with the meeting. After considerable discussion of the questions, more co-designers picked up sachets. After yet more discussion, the comfort level increased and co-designers began suggesting humorous changes to the questionnaire. For example, one question asked: "who is protesting the Alberta oil sands?" We were exploring student geographic knowledge about Indigenous people near the oil sands. The co-designers self-deprecatingly (but also proudly) proposed teasing students with one of the incorrect answers: "write 'Mohawks.' 'They'll choose that one 'because Mohawks are always protesting everything!'." Participants may have been waiting for our intentions to clarify and to witness deep listening before accepting any gifts. Their uncertainty about our intentions and our cultural awkwardness around gift-giving was resolved through discussion, with laughter marking a moment of transition for many. By the end of the meeting everyone had taken the tobacco.

We felt the power of humour again in the second co-design meeting, at a friendship centre in southwestern Ontario. In this meeting, humour challenged academic authority and restored mutual respect. One woman challenged a test question asking which province is home to the greatest number of status First Nations individuals, recommending that we move away from status First Nations. Anne explained that in that question we concentrated on status First Nations because Indian status is the focus of government population statistics, and suggested alternative terminology. ${ }^{3}$

${ }^{3}$ Under the Indian Act the federal government in Canada retains unilateral authority to define who can be considered legally "Indian." These definitions of Indian status privilege the male 
The co-designer repeatedly rejected these alternatives and, one by one, all the words in between, eventually to the extent that silence became the only possible response. During this prolonged exchange the six other group members watched in silence. Finally, Anne turned and exclaimed "you're yanking my chain!" She grinned and replied "yes, I am!" There was laughter and the tension eased. The exchange was much less about the question than about the entanglement of academic knowledge and colonial power, that who has the right to define always matters, that silence is often respectful, and that humour works in powerful ways. A few meetings later, we dropped this question entirely as it worked to reinforce colonial definitions of identity.

Sometimes humour acknowledged challenges and milestones in communicating across experience. In a meeting early on in the process at a southwestern Ontario university, a co-designer patiently helped us clarify wording and develop new questions. Halfway through review of the questions, during discussion of a question on systemic racism, he suggested that there were other manifestations of systemic racism not included in our answer. Through discussion the structure of the question changed to all-ofthe-answers-are-correct. After Anne suggested a possible third correct answer, he turned to her and asked "can you lift up your hair?" There was a beat of perplexed silence and he said with a smile "I want to see how many ears you are hiding under there!" There was laughter and the meeting proceeded with renewed energy.

\section{Challenging Colonial Epistemological Inheritance}

The critical perspectives of Indigenous educators and community members transformed epistemological assumptions underpinning the survey in key ways. While we had initially conceived of the project in fairly static terms how much do students know, how does that knowledge, or lack thereof, compare across provinces - co-design transformed the questionnaire into a living educational tool, grounded in the experiences, histories, and networks of relationships with and of the people and places we worked with (Malpas, 1999; Wilson, 2008). Co-designers' critical perspectives revealed entrenched colonial epistemological language in the questionnaire. They also deconstructed assumptions of static knowledge, making clear how notions of fixity work for colonialism. These changes allowed us to refine language that would likewise challenge the thinking of students.

lineage, resulting in profound gender inequalities with on-going assimilative effects (Lawrence, 2004). 


\section{The Importance of Place}

Just as we had experienced with the questionnaire we co-designed in Newfoundland and Labrador, meetings with co-designers in Ontario foregrounded embodied and emplaced experience and enhanced our understanding of the diversity and specificity of Indigenous experience in different parts of Canada. We had chosen to open the Ontario questionnaire with questions about Indigenous presence adapted from our work in Newfoundland and Labrador: what was the reserve closest to the university campus, and could the students identify the locations of three named Indigenous communities on a numbered map of communities in the province? In the Newfoundland study, through these questions and especially the map we sought to challenge the deeply held prejudice that there are no Indigenous peoples on the island, a mythology perpetuated in the Newfoundland and Labrador curriculum (Godlewska, Rose, Schaefli, Freake \& Massey, 2016; Hanrahan, 2003). In Ontario, co-designers preferred a question on traditional territory, based in Indigenous definitions of belonging. We soon dropped the reserve question as reserve location is much less important to student awareness than traditional territory, and anyway, when there are multiple reserves near campus, as is the case in much of Ontario, the question becomes technical, about knowledge of distance rather than awareness of time immemorial presence. With that question gone, the map question seemed to us even more important. We were particularly attached to it because we had devoted resources to the map's construction and at that time were still preoccupied with maintaining comparability between provinces. But co-designers often thought the map question too difficult (and it was). It took another month and three more sets of meetings before we dropped the map question and understood traditional territory as replacing both it and the reserve question. Focusing on reserves risked evacuating traditional and pre-Indian Act forms of Indigenous governance and authority. It also risked perpetuating colonial discourses of authenticity that present reserve culture as the primary and only culture of Indigenous peoples. Cartesian representational strategies cannot do justice to the diversity of Indigenous experience. Provincial contexts matter as do local realities.

The range of experience we encountered also broadened the scope of the questionnaire, a development that deepened our conceptualization of the issues at hand while making the questions more reflective of the diversity of Indigenous experience. We initially phrased a question on changes in legal definitions of Indian status as "Why might federal government changes in legal definitions of status lead to divisions within and between communities?" This decision was rooted in our experiences in Newfoundland and Labrador, where we felt co-designers' anger at often arbitrary, punitive and exclusionary government definitions of identity and belonging. In Ontario, a very different rights environment, it became clear 
that changes in status definitions might sometimes also lead to greater community self-determination. The language of the question shifted to account for this: "What happens when there are changes in legal definitions of status?" with an all-of-the-answers-are-correct structure that included community self-determination as an answer. While our initial focus on the violence of status laws emerged out of the affective relations of co-design meetings in Newfoundland and Labrador, that broadened and deepened through engagements with other co-designers in different contexts (Ahmed, 2006). The living and iterative nature of co-design worked to disrupt assumptions of stasis and uniformity embedded in survey methodology.

\section{Colonial Prejudice is Systemic and Enduring}

Co-designing the questionnaire emphasized the depth and pervasiveness of colonial ignorance. Such ignorance is both a social and individual accomplishment. Institutionalized and promoted through education, law, political structures, and popular modes of representation, an epistemology of ignorance molds individuals and groups into performers of ignorance, even though they may not intend to exclude or to be excluded, or be aware of playing either part (Dotson, 2011; Fricker, 2007). It is also in an individual's self-interest to ignore the sources of privilege and how they shape circumstances for us and for others (Bell, 2008). Co-designing the questionnaire reinforced the importance of deep collaboration to shifting social worlds.

The critical perspectives of people we worked with deepened the language of the questionnaire to better account for the violence of the $19^{\text {th }}$ and $20^{\text {th }}$ century residential school system, a more than 100 -year government policy of forced removal of Indigenous children from their families for placement in under-resourced schools, dedicated to the assimilation of Indigenous children and communities and the clearing of land for Euro-Canadian settlement (TRC, 2015). When we began in Ontario, the questionnaire contained three questions on the residential schools: what was allowed in the schools, who ran the schools, and a question on the Prime Minister's 2008 apology. Co-designers sharpened the connection between the schools and cultural attack, suggesting that the question on what was allowed in the schools shift to focus on what was forbidden, and developing a new question on the contemporary consequences of the residential schools. They also turned these two questions into check-allthat-apply, in order to deepen the education of students about the intent and consequences of the schools, while ensuring that their selections are accurate reflections of their knowledge.

Co-design similarly broadened and deepened the questionnaire's treatment of systemic racism. In its first iteration on a pilot survey at our home university (in a town then housing nine prisons), a question focused 
on the overrepresentation of Indigenous people in prisons, with the aim of educating students about some of the systemic inequities in Canadian society (Rymhs, 2008). We dropped the question in Newfoundland and Labrador, as co-designers there felt that it would reinforce entrenched prejudices, but brought it back in Ontario after sharpening the question to focus on imprisonment as an indicator of systemic racism. Through codesign it became clear that it was most important to capture more of the many expressions of systemic racism, including biased policing and high numbers of missing and murdered Indigenous women. Co-designers' engagement made explicit the mutual entanglement of racism and on-going colonial violence.

Co-designers also emphasized continuity between past and present attacks on Indigenous land rights, asking that we add two questions: the first comparing when white women and First Nations and Inuit people were granted the right to vote, and the second focusing on early $20^{\text {th }}$ century government strategies to limit land claims. The aim of both questions was to challenge the prevailing misconception that Indigenous political action has emerged from nowhere in the last 50 years, by showing students how the Canadian government has consistently undermined Indigenous land rights, and until 1951, restricted avenues of resistance to that attack (Mathias \& Yabsley, 1991). Co-designers also challenged a question that emphasized the role of the Nisga'a nation in setting legal precedent for the recognition of Aboriginal title in Canada (Foster, Raven \& Webber, 2011). For the co-designers, what was most important about the Nisga'a settlement was the extinguishment of the Nisga'a's Aboriginal title. We initially did not change the correct answer, but through on-going conversations with codesigners on restrictions on Indigenous sovereignties imposed through the modern land claims process, we came to understand that the systemic nature of extinguishment policies and their use as a tool for land expropriation was indeed most important for students to know.

The failure of the federal government to recognize the systemic and enduring nature of colonialism became especially clear in the development of a question on Prime Minister Stephen Harper's 2008 Apology to Former Students of the Indian Residential Schools. Early on in the process, a codesigner told us that the correct answer as written did not capture the narrowness of the apology: the Prime Minister apologized only for the abuse and assimilative aims of the residential schools, not for the government's many attempts to eliminate Indigenous cultures and values, its failure to uphold treaty agreements, or its culpability in underfunding the schools, creating policies of forced attendance, and allowing widespread disease and abuse to continue despite knowledge of their existence (TRC, 2015). This discussion spanned our visit with these co-designers, as, while we were focused on the narrowness of the apology, our wording was not initially skilful enough to achieve the learning opportunity sought by codesigners. They wanted the right and the wrong answers to work together to 
emphasize how narrow the apology had been: there was no acknowledgement of the government's many attempts to eliminate Indigenous cultures and values; there was no recognition of the continuing colonial nature of many Canadian institutions (law, education, policing, etc.). The apology recognized only the abuse and the assimilative aims of the schools. This refusal to acknowledge the larger context, policies and ideologies that made the residential schools possible, and that perpetuate their harm, was so important it had to be spelled out with crystal clarity.

\section{Indigenous Peoples are Thriving and will Continue to Thrive}

Co-design foregrounded the importance of imagination to life and emphasized the fundamental link between language and epistemology. Questions came to emphasize Indigenous cosmologies, community selfdetermination, and language revitalization, decentering colonialism as the only story of Indigenous lives. We became more critical of the epistemology underpinning government statistics, and saw the importance of taking every possible opportunity in the questionnaire to challenge discourses of Indigenous decline (Tuck, 2009; Vizenor, 2008).

One of the most difficult questions to develop was on the meaning of land to Indigenous peoples. The process of developing a question that touches upon issues fundamental to Indigenous cosmology illuminated the endurance of Euro-colonial conceptions of space-time and the importance of challenging them (Cajete, 2000). We began in Ontario with a codesigned version of the question that focused on the notion of belonging: people belong to the land more than it belongs to them. Ontario codesigners told us early on in the process that Indigenous understandings of land were more about relating than belonging, but as at that stage in our thinking we could not find the language to express that, we made no change. A few meetings later, a co-designer again pointed out the centrality of relationships. He suggested that the question focus on what, traditionally, land represented for Indigenous peoples, and helped us phrase the correct answer. Another co-designer in the next meeting challenged the implication that Indigenous cosmology is not of the present. There, the question shifted to focus on what land continues to mean to Indigenous peoples. Still later on, co-designers suggested that the question avoid the traditional/modern dichotomy altogether, by focusing on the meaning of "all my relations," a phrasing that emphasizes the relational nature not only of land, but of being. The iterative and prolonged struggle across co-design meetings speaks to the power of the extended conversation that is co-design and the opportunity that such meetings create for bringing into relationship diverse ways of understanding.

People we worked with also emphasized community self-determination, which led to the replacement of anything suggestive of decline in 
Indigenous vitality. In a questionnaire about oppression and colonialism, there was a tendency to the negative. Co-designers felt that, while necessary, given the depths of colonial ignorance prevailing in Canada, it had to be mitigated with a new check-all-that-apply question on the positive changes driven by Indigenous people(s). Experiences beyond Ontario informed this interaction and the insights of co-designers in Ontario have informed continued work to focus on Indigenous resurgence and power.

The process of developing a question on Indigenous languages emphasized in particular the importance of not contributing to discourses of Indigenous decline, and made us much more critical of the claims to expertise embedded in government-generated statistics. Co-designers were very critical of a question on the number of endangered and viable Indigenous languages in Canada today. The goal of the question was to educate students about one of the most violent aspects of colonialism. In formulating it, we relied on data collected by linguists and statisticians at Statistics Canada. Early on, some co-designers expressed anger at the implication that despite significant community-based language revitalization, some Indigenous languages might not survive. It took us some time to hear the essence of their critique and move away from statistics and a focus on loss. In later meetings, when people pointed out that the question, as phrased, was not explicit about the source of its information, nor did it give students a sense of the number of Indigenous languages spoken before European contact, the question became more explanatory and shifted to focus on the three most widely spoken Indigenous languages. Most recently, co-designers' insights have led us to rewrite the question to focus on language learning. However, this change has not been without controversy, as some co-designers want to celebrate achievements in this regard and others want the gravity of the situation made clear.

\section{Treaties are Living and Entail Responsibility to Engage}

Through co-design the questionnaire also came to emphasize the treaty responsibilities of all governments and people in Canada. Through words and actions, people we worked with highlighted the living nature of treaty obligations, challenging the historical imagination perpetuated in Canadian law, and in provincial curricula and teacher education programs, that treaties are singular events with little contemporary relevance (Borrows \& Coyle, 2017). In discussion of a question on government resettlement of Indigenous communities, co-designers pointed out that not all resettlement took place without prior consultation: treaties such as the Robinson-

Superior Treaty and Treaty 3 involved extended negotiation on the part of Anishinaabe leaders for reserve land, annuities, and unencumbered hunting and fishing rights, all to ensure long-term cultural and political autonomy 
(Long, 2010). Co-designers recommended that we focus instead on why treaties were signed in the first place, which led us to replace the resettlement question with a question on the difference between reserves and traditional territory. This is a question that has survived translation into multiple jurisdictions across the country, which would certainly not have been the fate of any question on treaties.

The people we worked with also emphasized the living nature of treaty obligations, challenging the "settled expectations" and "fantasies of entitlement" so often mobilized by residents of Canada to deny even the possibility of Indigenous sovereignty and self-determination (Mackey, 2016). We began in Ontario with a question on who in Canada is affected by treaties, the correct answer to which was "All people living in Canada." Co-designers initially recommended focusing on responsibility: "affected by treaties" was replaced with "obligation to uphold treaties." Other people then made the question more explanatory and more precise, arguing that as treaties are nation-to-nation agreements, the correct answer should distinguish between governments and people, and between First Nations, Métis and Inuit governments and the government of Canada. Co-designers also challenged the widely-held prejudice that First Nations and Inuit students receive free post-secondary education, by emphasizing treaty obligations in a question on the post-secondary education funding available to First Nations and Inuit students. Treaty language in the questionnaire worked to disrupt narratives of liberal-multicultural equality that omit from visions of justice the centrality of treaties and the on-going relationships of critical historical consciousness, respect and responsibility they entail (Borrows \& Coyle, 2017).

\section{Balancing Social Worlds}

Sometimes co-designing the questionnaire involved disagreement over what students should be expected to know. Discussing these differences made the questionnaire more reflective of the diversity of co-designers' knowledge and experiences, and consequently a much better instrument. Identity terminology was an important concern. Some people preferred using "Indian" (in quotation marks) to signal the term's failure to encompass Indigenous forms of identity and value. Others saw no need for quotation marks as students should understand that Indian continues to be used by the government of Canada to define Indigenous identity. We followed the majority preference and used quotation marks.

Disagreement also revolved around whether questions were too easy or too difficult. Co-designers were willing to drop a question on whether the First Nations, Métis and Inuit population is increasing or decreasing, as to them the answer was obvious. However, our findings so far suggest the importance of the question: the vanishing Indian myth is alive and well 
amongst first year university students in Ontario and Newfoundland and Labrador and this is linked to the portrayal of Indigenous peoples in Ministry-approved curricula and texts (Godlewska, Rose, Schaefli, Freake \& Massey, 2016; Schaefli, Godlewska \& Rose, 2018; Schaefli, Godlewska $\&$ Lamb, 2019). Sometimes disagreement centred on what students should be expected to know about Indigenous cultures. Some co-designers stressed the importance of questions on Indigenous cultural practices and teachings. Other co-designers were not comfortable with the prospect of exposing traditional knowledge. We chose ultimately to focus culture questions on language, cultural persistence, and Indigenous contributions to the arts. Recently, through work with St. Lawrence College in Ontario (Anishinaabe and Haudenosaunee territories) and with Vancouver Island University (Snuneymuxw territory) and Douglas College (Kwikwetlem, and Sto:lo territories) in British Columbia, we have begun to formulate questions that reflect the wisdom of Indigenous ways of thinking and being, with the aim of showing students their vitality and importance. We will continue to develop such questions as the project moves to other provinces. Disagreements reinforced the importance of mutual autonomy and respect to strong relationships, demonstrating the importance of co-design to the development of richer approaches to social reality. This living process of challenge, discussion, and reframing is why the Awareness questionnaire cannot, and should not, be created from book knowledge. While books and academic journals are invaluable sources of learning, they are necessarily limited in their scope, content, and voice. The affects engendered through reading written text are also different from those that emerge from face-toface engagement. As a research tool that is fundamentally about decolonizing knowledge, it is vital that the questionnaire reflect many minds and many different experiences.

\section{Conclusion}

This article has traced shifts in language and consciousness generated through co-design of a questionnaire aimed at assessing how Canadian post-secondary students have learned to think about colonialism and its relationship to Indigenous peoples and Canadian society. The questionnaire has challenged student learning in post-secondary institutions during a period of engagement (at various levels) with the work of the Truth and Reconciliation Commission (2009-2015). Co-designing the questionnaire in place with Indigenous community leaders and educators transformed it into a powerful educational tool that emphasized the systemic nature of colonial violence, the failure of colonial modes of categorization to define Indigenous identities and territories, the vitality of Indigenous languages and cosmologies, and the living nature and importance of nation-to-nation relations. In on-going negotiation of language with Indigenous educators 
and community members our own sensitivities and imaginations shifted, as the questionnaire began to encompass the language and imagination with which to challenge colonial ignorance and convey the diversity, vitality and strength of Indigenous peoples in ways that encourage student selfreflection and education.

The shifts described here attest to the social importance of research tools grounded in rich conversations and diverse experiences. They also raise important questions about voice and benefit. Given the number, duration, and complexity of the meetings, the account given here is necessarily partial and fragmented. While we suggested co-authorship to co-designers, academic publication was not important to most, revealing the limits of an economy of value rooted in academic social worlds. We have since moved to other forms of reciprocity. Métis artist and Elder Maria Campbell speaks to the responsibilities of researchers: "Reciprocity is a big teaching in our community, that what you take, you have to give back. And there are responsibilities to taking people's power... whether it's their stories or their friendship, or just making a place in the community . . . you can't just go and take that power. You'll get sick..." (Campbell quoted in Dewar, Gaertner, Goto, Mathur \& McCall, 2013, p. 15). We continue to carry with us the wisdom of careful listening, relinquishing control, and attending to the limits of thinking and being to fostering decolonizing relations. These gifts have shaped the Awareness project as well as our on-going efforts to share the project and its findings in ways that support the decolonization of education in Canada. The process is necessarily fraught and complex, as intention and goodwill do not in themselves constitute the ground or endpoint of decolonization (Ahmed, 2005; de Leeuw, Greenwood \& Lindsay, 2013). We have found, though, that the task of finding language to share knowledge in non-violent ways requires the best of everyone involved: humility, openness, generosity, humour, and vision of what we want to move towards. The capacity to learn and change our minds is perhaps the most important tool we all have.

\section{References}

Ahmed, S. (2005). The politics of bad feeling. Australian Critical Race \& Whiteness Studies Association Journal, 1(1), 72-85.

Ahmed, S. (2006). Orientations: Toward a queer phenomenology. GLQ: A Journal of Lesbian \& Gay Studies, 12(4), 543-574.

Assembly of First Nations. (1972). Indian control of Indian education: Policy paper presented to the Minister of Indian Affairs and Northern Development. Ottawa: Ministry of Indian Affairs \& Northern Development.

Assembly of First Nations. (1988). Tradition and education: Towards a vision of our future A declaration of First Nations jurisdiction over education. Ottawa, ON: Ministry of Indian Affairs and Northern Development.

Battiste, M. (2013). Decolonizing education: Nourishing the learning spirit. Saskatoon, SK: Purich Press. 
Bell, A. (2008). Recognition or ethics? De/centering and the legacy of settler colonialism. Cultural Studies, 22(6), 850-869.

Bodone, F., Gudónsdóttir, H., \& Dalmau, M. (2004). Revisioning and recreating practice: Collaboration in self-study. In J. Loughran, M. Hamilton, V. LaBoskey, \& T. Russell (Eds.) International handbook of self-study of teaching and teacher education (pp. 743784). London: Kluwer.

Borrows, J., \& Coyle, M. (2017). The right relationship: Reimagining the implementation of historical treaties. Toronto, ON: University of Toronto Press.

CAAS. (2004). Learning about Walking in Beauty: placing Aboriginal perspectives in Canadian classrooms. Toronto, ON: Canadian Race Relations Foundation (CRRF) for the Coalition for the Advancement of Aboriginal Studies.

Cajete, G. (2000). Native science: Natural laws of interdependence. Santa Fe, NM: Clear Light Pub.

Calderon, D. (2014). Uncovering settler grammars in curriculum. Educational Studies, 50(4), 313-338.

Chakrabarty, D. (2009). Provincializing Europe: Postcolonial thought and historical difference. Princeton, NJ: Princeton University Press.

Daza, S.L. (2008). Decolonizing researcher authenticity. Race, Ethnicity \& Education, 11(1), 71-85.

de Leeuw, S., Greenwood, M., \& Lindsay, N. (2013). Troubling good intentions. Settler Colonial Studies, 3(3-4), 381-394.

Denzin, N. K., Lincoln, Y. S., \& Smith, L. T. (Eds.). (2008). Handbook of critical and Indigenous methodologies. Thousand Oaks, CA: Sage.

de Sousa Santos, B. (2015). Epistemologies of the South: Justice against epistemicide. London: Routledge.

Dewar, J., Gaertner, D., Goto, A., Mathur, A., \& McCall, S. (2013). Practicing reconciliation - A collaborative study of Aboriginal art, resistance and cultural politics. Report commissioned by the Truth and Reconciliation Commission on Indian Residential Schools. Kamloops, BC: CiCAC Press.

Dhamoon, R. (2015). A feminist approach to decolonizing anti-racism: Rethinking transnationalism, intersectionality, and settler colonialism. Feral Feminisms, 4, 20-37.

Donald, D. (2012). Indigenous Métissage: a decolonizing research sensibility. International Journal of Qualitative Studies in Education, 25(5), 533-555.

Dotson, K. (2011). Tracking epistemic violence, tracking practices of silencing. Hypatia, 26(2), 236-257.

Ettlinger, N. (2011). Governmentality as epistemology. Annals of the Association of American Geographers, 101(3), 537-560.

Fabian, J. (1982). Time and the other: How anthropology makes its object. New York: Columbia University Press.

Fanon, F. (1967). Black skin, white masks. New York: Grove Press.

Foster, H., Raven, H., \& Webber, J. (Eds.). 2011. Let right be done: Aboriginal title, the Calder case, and the future of Indigenous rights. Vancouver, BC: UBC Press.

Fricker, M. (2007). Epistemic injustice: Power and the ethics of knowing. New York: Oxford University Press.

Godlewska, A., \& Smith, N. (Eds.). (1994). Geography and empire: Critical studies in the history of geography. Oxford: Blackwell Publishing.

Godlewska, A., Rose, J. Schaefli, L., Freake, S., \& Massey, J. (2016). First Nations, Métis and Inuit presence in the Newfoundland and Labrador curriculum. Race Ethnicity \& Education, 20(4), 446-462.

Godlewska, A., Schaefli, 1., Massey, J., Freake, S., Adjei, J., Rose, J., \& Hudson, C. (2017). What do first-year university students in Newfoundland and Labrador know about Aboriginal peoples and topics? The Canadian Geographer, 61(4), 579-594.

Godlewska, A., Schaefli, L., Massey, J., Freake, S., \& Rose, J. (2017). Awareness of Indigenous peoples in Newfoundland and Labrador: Memorial's first year students (2013) speak. The Canadian Geographer, 61(4), 595-609. 
Hanrahan, M. (2003). The lasting breach: The omission of Aboriginal people from the Terms of Union between Newfoundland and Canada and its ongoing impacts. St. John's: Government of Newfoundland \& Labrador.

Jones, A., with Jenkins, K. (2008). Rethinking collaboration: Working the indigene-colonizer hyphen. In N. K. Denzin, Y. Lincoln \& L. T. Smith (Eds.), Handbook of critical Indigenous methodologies (pp. 471-486). Thousand Oaks, CA: Sage.

Kirkness, V. J. (1999). Aboriginal education in Canada: A retrospective and a prospective. Journal of American Indian Education, 39(1), 14-30.

Kovach, M. (2010). Indigenous methodologies: Characteristics, conversations, and contexts. Toronto, ON: University of Toronto Press.

Kuokkanen, R. (2008). Globalization as racialized, sexualized violence. International Feminist Journal of Politics, 10(2), 216-233.

Kuokkanen, R. (2011). Reshaping the university: Responsibility, Indigenous epistemes, and the logic of the gift. Vancouver, BC: UBC Press.

Lawrence, B. (2004). "Real" Indians and others: Mixed-blood urban Native peoples and indigenous nationhood. Lincoln, NB: University of Nebraska Press.

Long, J. S. (2010). Treaty no. 9: Making the agreement to share the land in far northern Ontario in 1905. Montreal, QC: McGill-Queen's University Press.

Louis, R. P. (2007). Can you hear us now? Voices from the margin: Using indigenous methodologies in geographic research. Geographical Research, 45(2), 130-139.

Mackey, E. (2016). Unsettled expectations: Uncertainty, land and settler decolonization. Winnipeg, MN: Fernwood Publishing.

Maldonado-Torres, N. (2007). On the coloniality of being: Contributions to the development of a concept. Cultural Studies, 21(2-3), 240-270.

Mallon, F. E. (Ed.). (2011). Decolonizing Native histories: Collaboration, knowledge, and language in the Americas. Raleigh, NC: Duke University Press.

Malpas, J. E. (1999). Place and experience: A philosophical topography. Cambridge: Cambridge University Press.

Manuel, A., \& Derrickson, R. (2017). The reconciliation manifesto: Recovering the land, rebuilding the economy. Toronto, ON: James Lorimer \& Company, Ltd.

Mathias, J., \& Yabsley, G.R. (1991). Conspiracy of legislation: The suppression of Indian rights in Canada. BC Studies, 89, 34-45.

May, V. M. (2006). Trauma in paradise: Willful and strategic ignorance in Cereus Blooms at Night. Hypatia, 21(3), 107-135.

Medina, J. (2012). The epistemology of resistance: Gender and racial oppression, epistemic injustice, and the social imagination. Oxford: Oxford University Press.

Moreton-Robinson, A. (2015). The white possessive: Property, power, and Indigenous sovereignty. Minneapolis, MN: University of Minnesota Press.

Mountz, A., Miyares, I. M., Wright, R., \& Bailey, A. (2003). Methodologically becoming: Power, knowledge and team research. Gender, Place \& Culture, 10(1), 29-46.

Nicoll, F. (2004). Reconciliation in and out of perspective: White knowing, seeing, curating and being at home in and against Indigenous sovereignty. In A. Moreton-Robinson (Ed.), Whitening race: Essays in social and cultural criticism (pp. 17-31). Sydney: Aboriginal Studies Press.

Norris, J. (2008). Duo-ethnography. In E. F. Provenzo, Jr. (Ed.), Encyclopedia of the social and cultural foundations of education. Thousand Oaks, CA: Sage.

Patel, L. (2014). Countering coloniality in educational research: From ownership to answerability. Educational Studies, 50(4), 357-377.

Povinelli, E. (2011). Economies of abandonment: Social belonging and endurance in late liberalism. Raleigh, NC: Duke University Press.

Regan, P. (2010). Unsettling the settler within: Indian residential schools, truth telling, and reconciliation in Canada. Vancouver, BC: UBC Press.

Redwing-Saunders, S., \& Hill, S. M. (2007). Native education and in-classroom coalitionbuilding: Factors and models in delivering an equitous authentic education. Canadian Journal of Education, 30(4), 1015-1045.

Studies in Social Justice, Volume 13, Issue 2, 221-243, 2019 
Rymhs, D. (2008). From the iron house: Imprisonment in First Nations writing. Waterloo, ON: Wilfrid Laurier University Press.

Schaefli, L., \& Godlewska, A. (2014). Social ignorance and Indigenous exclusion: public voices in the province of Quebec, Canada. Settler Colonial Studies, 4(3), 227-244.

Schaefli, L., Godlewska, A., Korteweg, L., Coombs, A., Morcom, L., \& Rose, J. (2018). What do first-year university students in Ontario, Canada, know about First Nations, Métis, and Inuit peoples and topics? Canadian Journal of Education, 41(3), 688-725.

Schaefli, L., Godlewska, A., \& Rose, J. (2018). Coming to know Indigeneity: Epistemologies of ignorance in the 2003-2015 Ontario Canadian and World Studies Curriculum. Curriculum Inquiry, 48(4), 475-498.

Schaefli, L., Godlewska, A., \& Lamb, C. (2019). Securing Indigenous dispossession through education: An analysis of Canadian curricula and textbooks. In H. Jahnke, C. Kramer \& P. Meusburger (Eds.), Geographies of schooling (pp. 145-161). Berlin: SpringerOpen.

Sinclair, M. (2015, December 15). Justice Murray Sinclair's remarks on the Truth and Reconciliation report. Maclean's. Retrieved from http://www.macleans.ca/news/canada/justice-murray-sinclairs-remarks-on-the-truth-andreconciliation-report/

Smith, A. (2012). Indigeneity, settler colonialism, white supremacy. In D. HoSang, O. LaBennett, \& L. Pulido (Eds.), Racial formation in the 21st century (pp. 66-90). Berkeley, CA: University of California Press.

Smith, L. T. (1999). Decolonizing methodologies: Research and Indigenous peoples. London: Zed Books.

Steyn, M. (2012). The ignorance contract: Recollections of apartheid childhoods and the construction of epistemologies of ignorance. Identities, 19(1), 8-25.

Stoler, A. L. (2016). Duress: Imperial durabilities in our times. Durham, NC: Duke University Press.

Sullivan, S., \& Tuana, N. (Eds.). (2007). Race and epistemologies of ignorance. Albany, NY: SUNY Press.

TRC (Truth \& Reconciliation Commission of Canada). (2015). Final Report: Honouring the Truth, Reconciling for the Future. Winnipeg, MN: Truth \& Reconciliation Commission of Canada. Retrieved from http://nctr.ca/assets/reports/Final\%20Reports/Executive_Summary_English_Web.pdf

Tuck, E. (2009). Suspending damage: A letter to communities. Harvard Educational Review 79(3), 409-427.

Tuck, E., \& Yang, K. W. (2012). Decolonization is not a metaphor. Decolonization: Indigeneity, Education, \& Society, 1(1), 1-40.

Turner, D. A. (2006). This is not a peace pipe: Towards a critical Indigenous philosophy. Toronto, ON: University of Toronto Press.

Vizenor, G. (ed.). (2008). Survivance: Narratives of Native presence. Lincoln, NB: University of Nebraska Press.

Wa Thiong'o, N. (1994). Decolonising the mind: The politics of language in African literature. Nairobi: East African Publishers.

Wilson, D. D., Restoule, J. P. (2010). Tobacco ties: The relationship of the sacred to research. Canadian Journal of Native Education, 33(1), 29-45.

Wilson, S. (2008) Research is ceremony: Indigenous research methods. Halifax, NS \& Winnipeg, MN: Fernwood Publishing. 